\title{
A brief analysis of parenteral medicines delivered in community pharmacies for off-label use in pediatrics
}

\author{
Elena DINTE, Dana MATEI, Teodora ZEHAN \\ Department of Pharmaceutical Technology and Biopharmaceutics, Faculty of Pharmacy, \\ "Iuliu Hatieganu" University of Medicine and Pharmacy, Cluj-Napoca, Romania
}

\begin{abstract}
Objectives. The current paper aims to obtain an overview regarding the use of parenteral medicines recommended for the pediatric sector and delivered in Romanian community pharmacies.

Materials and methods. A retrospective observational study was developed, based on a questionnaire which was distributed in community pharmacies in Romania.

Results. The parenteral medicines were delivered in 100 community pharmacies which partake in the study, and which are distributed in 22 counties in Romania. The total number of parenteral medicines considered in the study were aimed for pediatric use and they represented approximately $5 \%$ of the total number of medicines prescribed for children delivered in the respective pharmacies. Of these, most of them are medicines authorized for adults, delivered for off-label use, by other routes of administration, in their original form or reformulated in the form of other pharmaceutical preparations, during the compounding activity in the pharmacy.

Conclusions. The parenteral medications most prescribed for pediatric use and delivered in community pharmacies are injectable solutions and powders for parenteral use. They are used as off-label medication in children, by other routes of administration, both to capitalize the therapeutic action of the active principle, and also as a vehicle for other medications with oral route or external route of administration.
\end{abstract}

Keywords: pediatric care, off-label drugs, parenteral administration, community pharmacy

\section{INTRODUCTION}

Parenteral administration of medicines in the pediatric population represents the most frequent approach in pediatric therapy, being justified in very young children, in those with serious or clinically unstable conditions, but also in the case of therapy destined for pathologies with symptoms (such as nausea, vomiting) which contraindicate the oral route of administration.
The choice of parenteral route of administration (intravenous, subcutaneous, or intramuscular injection, infusion) is highly influenced by the patient's condition, biopharmaceutical properties of the active substance, desired clinical effect, degree of tolerance for the medicine, as well as the child's compliance. It is also necessary to take into consideration the use of medical devices (such as micro-needles or needleless injections), especially for 
medicines which are administered frequently or long-term $(1,2)$.

The pharmacist can play an important role in establishing the details related to the parenteral administration of medicines in the pediatric population, by bringing valuable information to the medical team, in order to choose the correct dosage, duration of therapy, while taking into consideration the age and the body mass of the child. In intravenous administration (central or peripheral), it is necessary to describe and justify all the elements that ensure the safe administration of medication: injection site, injected volumes, administration rate, solution's viscosity, $\mathrm{pH}$, buffering in the solution, osmolarity, and of course including the characteristics of administration devices (needle thickness and length). In general, the administration of parenteral medicines is performed in healthcare units (such as hospitals, medical offices), in the outpatient department, and in some exceptional situations, at home, but, in all cases, the act of administration is performed only by trained professionals. The medicines administered parenterally to children, and not only, should be authorized for this purpose, because the pediatric population cannot be considered as a very young adult population, nor can it be considered as an independent and homogenous group, as clinical trials in adults are not necessarily predictable for children $(1,3,4)$. Several laws and regulations have been adopted which govern the development of pharmaceutical dosage forms which facilitate the administration of a wider range of doses adapted to children of different ages.

The publication in $\mathbf{2 0 0 2}$ of the declaration of the American Academy of Pediatrics on the off-label consumption of medicine in pediatrics, and the entry into force in 2007, in all European Union countries, of the „Pediatric Regulation” (Regulation (EC) No 1901/2006 of the European Parliament and of the Council, amending Regulation (CEE) No 1768/92, Directive 2001/20/EC, Directive 2001/83/EC and Regulation (EC) No 726/2004), aimed to facilitate, develop and increase access to medicines specially designed for children aged 0 to 18 years, to ensure that medicines used in the pediatric population are properly authorized for use in children and that they meet high quality standards regarding the ethical research, as well as supplementing available information on the use of drugs in children $(5,6)$. As a result of the adoption of regulations on the development of medicines for children, there has been observed a growth in the number of medicines approved with pediatric indications or in the number of those with extensive recommendations for use in pediatrics, which bring valuable information on safe use in children. However, the analysis of the current situation shows that many new drugs and a great majority of the molecules that have been already registered on the pharmaceutical market for a long time are not registered for pediatric use, and off-label drug use in the pediatric population remains an important problem $(6,7)$. As a result, in current clinical practice, children are frequently treated with medication designed and tested only in adults, many studies reporting off-label prescribing in the proportion of 9 to $78.7 \%$ in children and adolescents, the degree of use being higher in neonatal and pediatric care intensive units and in oncology departments, compared to primary care (8). Off-label use of medicines in pediatrics consists in prescribing them in different conditions than those for which they were authorized, concerning the child's age, the dose or the frequency of administration, the therapeutic indication, the route of administration and the pharmaceutical form (9). The off-label use of drugs in the pediatric population plays an important role in clinical practice, representing, in many situations, the only therapeutic option, and the treatment, even if it often involves some risks, is sometimes administered for long periods. This practice also has some implications, such as legal, clinical, and ethical ones, and it has a great impact on drug settlement by health insurance systems. Off-label prescription of drugs in children involves the responsibility of the prescribing physician (in terms of obtaining therapeutic efficiency, as well as the occurrence of side effects) and requires the informed consent of parents $(10,11)$.

The paper aims to obtain an overview regarding the use of parenteral drugs recommended for the pediatric sector and delivered in community pharmacies in Romania.

\section{MATERIALS AND METHODS}

A retrospective observational study was elaborated, based on a questionnaire which was distributed in community pharmacies in Romania, the criteria for inclusion in the study being the delivery of parenteral drugs prescribed for children in the respective pharmacies. The results obtained after completing the 


\section{Urban area Rural area}

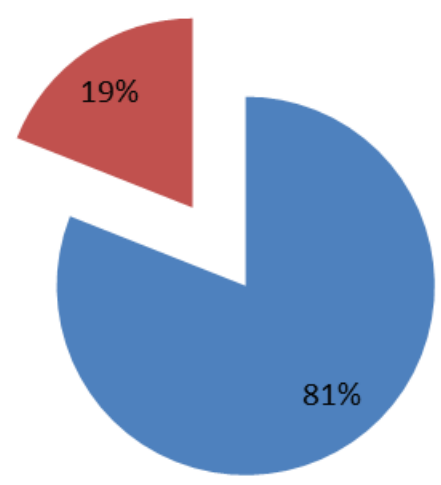

FIGURE 1. Distribution of responding community pharmacies in urban and rural areas

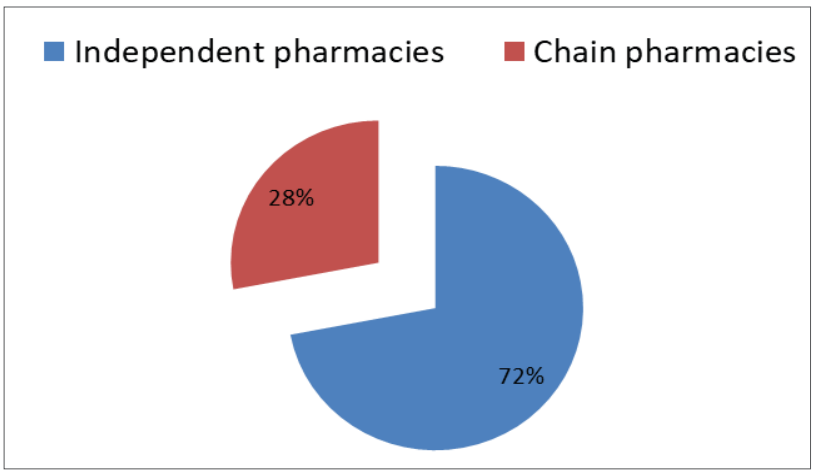

FIGURE 2. Type of responding pharmacies from the point of view of the authorization holder questionnaire were collected, analyzed, and interpreted. Data were expressed numerically and as a percentage in pharmaceutical dosage form units (ampoules, vials, bags etc.).

\section{RESULTS AND DISCUSSION}

Following the distribution of the questionnaire, 100 community pharmacies responded, of which $81 \%$ operate in urban areas and $19 \%$ in rural areas (Fig. 1). $72 \%$ of the community pharmacies enrolled in the study are owned by a pharmacist and represent independent pharmacies, and the remaining $28 \%$ belong to a national chain of pharmacies, being owned or managed by people who do not activate professionally as pharmacists (Fig. 2).

Regarding the seniority of the responding pharmacists, $51.46 \%$ of them have a length of practice of $1-10$ years, followed in proportion of $32.04 \%$ by pharmacists with a length of practice between 11-20 years, $8.74 \%$ with a length of practice of 21-30 years, $6.80 \%$ with a length of practice of $31-40$ years, and the senior pharmacists, with a length of practice of over 40 years, being present in the lowest proportion (Fig. 3). The results highlight that the chief pharmacists who participated in the study are mostly young, over

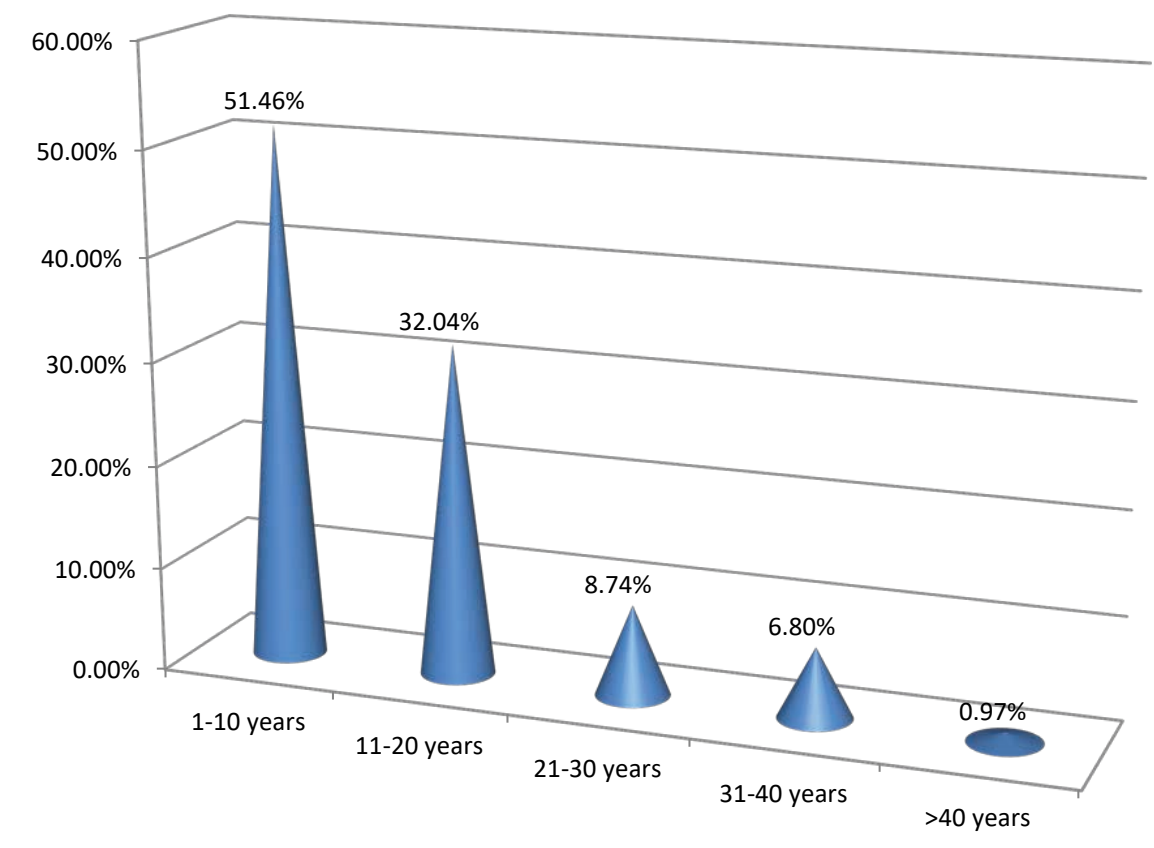

FIGURE 3. Professional experience (years) of responding pharmacists (\%) 
$80 \%$ of them with experience in the pharmaceutical field of up to 20 years. Pharmacists with a long experience in the profession, 30-40 years and slightly above this limit are, most likely, independent pharmacists who own the pharmacy and have chosen to continue their activity even if they have reached retirement age.

The questionnaires were distributed in 22 counties, most of the responding pharmacies being from Cluj county (26.21\%), followed by Brașov (12.62\%), Mureș (11.65\%), and Bihor (8.73\%) counties, the pharmacies from the other counties being present to a lesser extent (Fig. 4).

The study aimed to highlight the proportion of drugs used in pediatric therapy, delivered by the community pharmacies who responded to the questionnaire, represented as a percentage of the number of pharmaceutical dosage form units delivered by the respective pharmacy. Among the responding pharmacists, $25.24 \%$ state that $10 \%$ of the dispensed medicines are prescribed for children, $30.1 \%$ deliver for children only $15 \%$ of the total medicines dispensed in the pharmacy, and $21.36 \%$ deliver $20 \%$. About $15 \%$ of pharmacies deliver only $5 \%$, and a percentage of

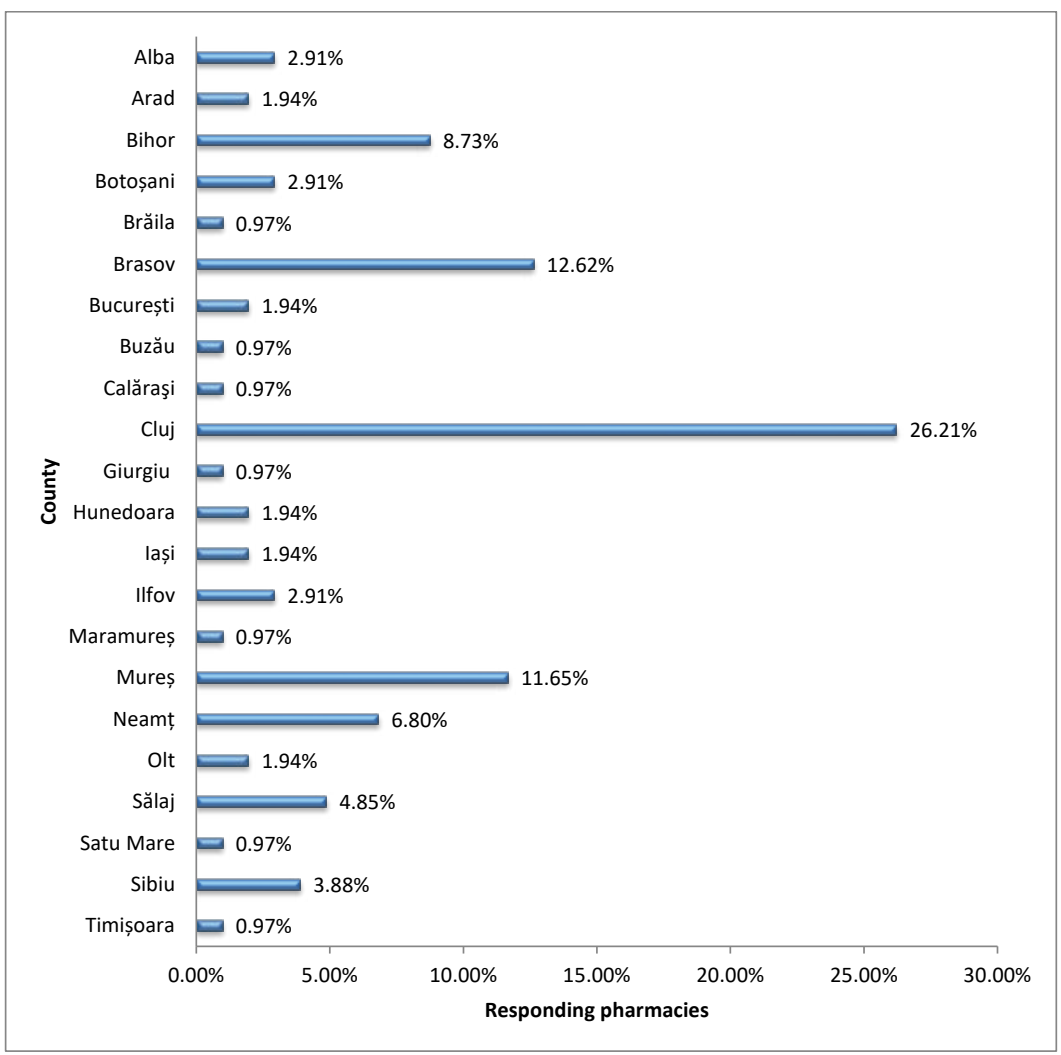

FIGURE 4. Distribution of responding pharmacies by counties
7.7\% deliver more medicines used by children, over $30 \%$. This increased percentage is explained by the fact that these pharmacies serve a geographical area with a well-represented pediatric population or are located near pediatric hospitals. The analysis of the results suggests that over $50 \%$ of the surveyed pharmacies deliver between $10 \%$ and $20 \%$ of medicines used in children, out of the total number of medicines dispensed to the population. In this category of drugs, pharmacists have included all pharmaceutical dosage forms intended for oral, cutaneous-mucosal, parenteral administration, prescription drugs and OTC medicines.

On the other hand, most pharmacists state that, out of the total number of medicines delivered for children, only $5 \%$ are parenteral medicines prescribed for the pediatric population (data not shown), and most preparations are dosage forms for adults, the parenteral preparations authorized for children being in an extremely small proportion.

This result can be explained by the fact that, in most cases, children are treated with parenteral medicines administered in health facilities, whose pharmacies are supplied with existing pediatric drugs, authorized for children. On the other hand, community pharmacies deliver parenteral medicines that are administered less often, in an outpatient setting or at home, in this way, these preparations being used most often off-label, by other routes of administration.

Based on these results, the distribution on pharmaceutical dosage forms of parenteral medicines delivered for off-label use in children was observed, and the results are presented in Fig. 6 .

Among the parenteral preparations authorized for adults, injectable solutions are the most used in off-label medication in children, in proportion of $45.61 \%$ of all parenteral medicines delivered for children. Parenteral powders are also frequently used, in a proportion of $28.08 \%$, followed by 


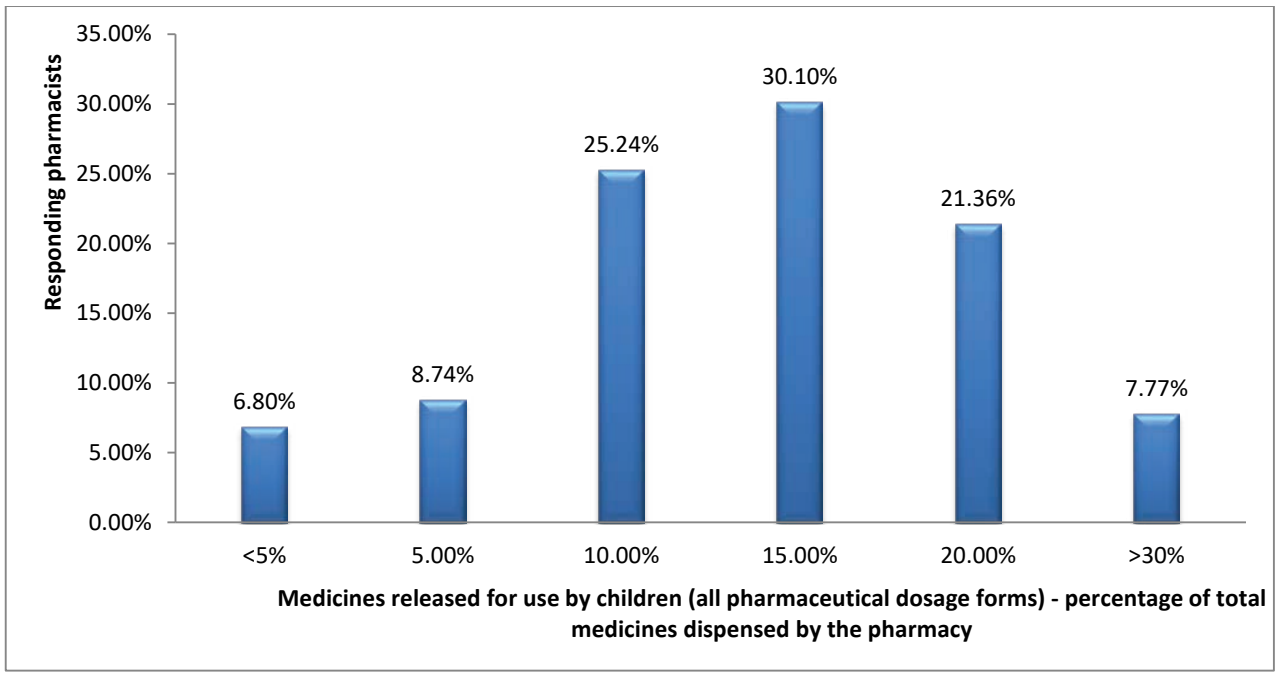

FIGURE 5. Recommended medicines in pediatrics, dispensed in the studied community pharmacies, expressed as a percentage of the total medicines delivered in the respective pharmacy (expressed in pharmaceutical dosage forms units) injectable suspensions $14.03 \%$ and, solutions for infusion, in a percentage of $12.28 \%$.

Obviously, in the case of vaccines (0\%), only the tested and authorized forms for the pediatric population are used.

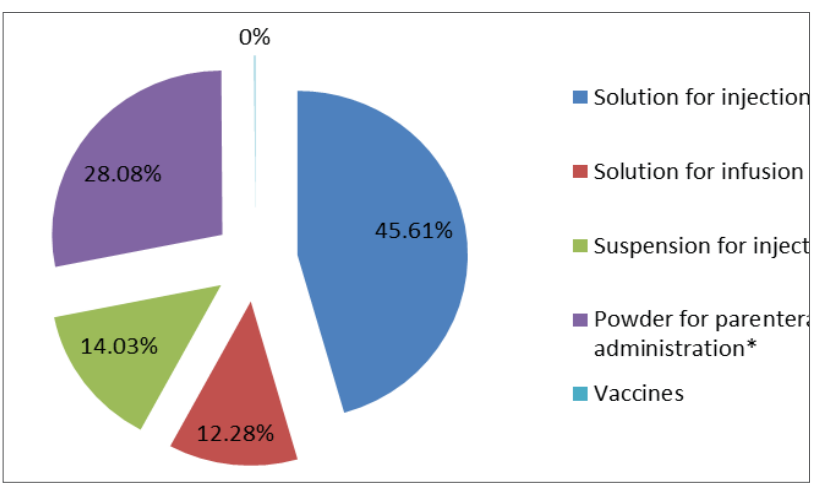

FIGURE 6. Distribution by pharmaceutical dosage forms of all parenteral medicines dispensed in community pharmacies for off-label use in the pediatric population

* are included: Powder for solution for injection/infusion, Powder for suspension for injection, Powder and solvent for solution/suspension for injection, Powder and solvent for solution for infusion

Parenteral preparations delivered in the community pharmacies included in the study, for off-label administration in children, are frequently used for another route of administration, except for a different therapeutic indication. Fig. 7a-b shows the distribution on pharmaceutical dosage forms of parenteral drugs delivered for off-label use in children, orally, respectively, by cutaneous-mucosal route (external administration, including inhalation).
Since therapeutic regimens in pediatrics may include various combinations of pharmaceutical drug substances and different doses, depending on the age of the child, it is obvious that in the case of molecules for which a pediatric medicine is not authorized, adult medicines are used, adjusting the doses accordingly. Off-label use also includes the administration of medicines on a different route of administration than that for which the medicine was authorized. This is also true in the case of parenteral medicines, and it is also reflected in figure 7a-b, which shows that in the Romanian community pharmacies surveyed, parenteral medicines that are delivered are administered by other routes of administration. The injectable solutions are delivered in the highest proportion $(56.3 \%$ of the total pharmaceutical dosage form units delivered for use in children) to be administered off-label orally, if no other pharmaceutical product is available (injectable solution of calcii gluconas $95 \mathrm{mg} / \mathrm{ml}$, for calcium intake, injectable solution of metamizolum natrium $1 \mathrm{~g} / 2 \mathrm{ml}$, for antipyretic action) (12), for various reasons, including lack of stocks of approved pediatric oral medicines. Also, other pharmaceutical forms can be used to harness the therapeutic effect of the active principles, for example injectable suspensions (12.60\%), parenteral powders (16.5\%), solution for infusion, in proportion of $14.60 \%$, (for example, mannitolum solution for infusion $200 \mathrm{~g} / \mathrm{l}$, administered orally for the purgative effect by osmotic mechanism) (12). The study shows that these pharmaceutical forms are prescribed off-label for external use also. For example, infusion solution are used in proportion of $15.50 \%$ for external use (electrolyte solutions for wound lavage). Injectable 


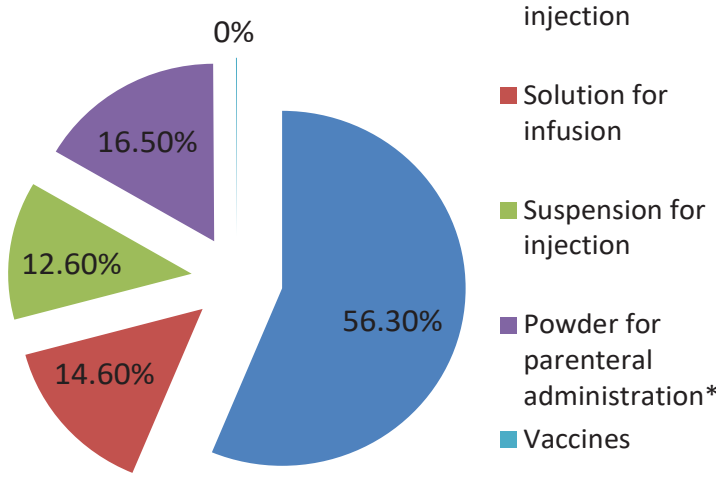

a. Off-label Oral administration

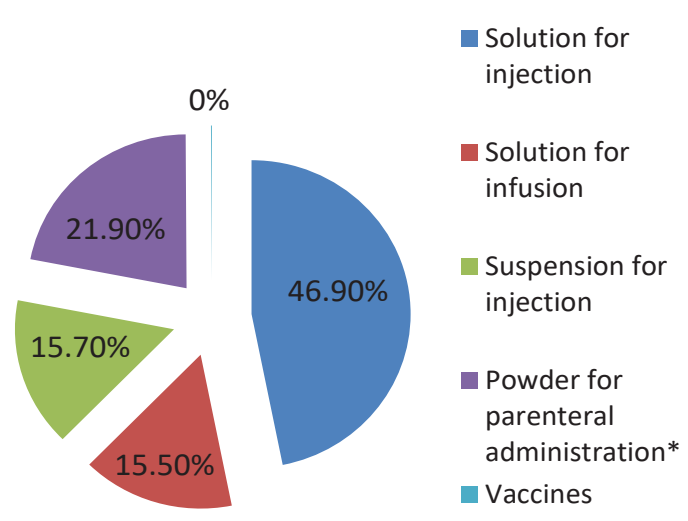

b. Off-label External administration

FIGURE 7. Distribution by pharmaceutical dosage forms of parenteral pharmaceutical products delivered in community pharmacies, for off-label use in the pediatric population, for a different route of administration than the authorized one: a. Oral administration; b. External administration

solutions are most frequently used in external application (46.90\%), followed by parenteral powders (21.9\%), and then by injectable suspensions (15.7\%), some for valuing the pharmacological effect of the active principles (steroidal and non-steroidal antiinflammatory preparations, antibiotics, etc.), other as vehicles for other preparations (injectable solution of sodium chloridum $9 \mathrm{mg} / \mathrm{ml}$ ) (12). Among the pharmacies included in the study, about a third said they carry out compounding activity, during which they prepare medicines with application on the skin and mucosae for children, using parenteral preparations. Many of the industrial injectable solutions, suspensions and powders are incorporated in other solutions with external application (nasal, auricular, or ophthalmic solutions), suppositories, or semi-solid preparations.

\section{CONCLUSIONS}

This study evaluated the use of parenteral medicines delivered for administration to children in 100 community pharmacies distributed in 22 counties in Romania. The study highlighted that in the community pharmacies included in the study, parenteral medicines are delivered for pediatric use, but most of them are medicines authorized for adults, being used off-label in children, by a different route of administration, orally or externally. The most frequently prescribed medicines are injectable solutions and parenteral powders, used both to capitalize on the therapeutic action of the active principle and as a vehicle for other pharmaceutical dosage forms compounded in the pharmacy.

Conflict of interest: none declared Financial support: none declared

\section{REFERENCES}

1. Guideline on pharmaceutical development of medicines for paediatric use EMA/CHMP/QWP/805880/2012 Rev. 2. Internet. Available at: https://www.google.com/search?client=firefox-b-d\&q=Guideline+on+pharmaceutical+development+of+medicines+for+paediatric+use+EMA\%2FCHM-

P\%2FQWP\%2F805880\%2F2012+Rev.+2. Accessed on June 2021.

2. Palmaro A, Bissuel R, Renaud N, Durrieu G, Escourrou B, Oustric S, Montastruc J-L, Lapeyre-Mestre M, Off-label prescribing in pediatric outpatients. Pediatrics. 2015;135(1):49-58.

3. Allen HC, Garbe MC, Lees J, Aziz N, Chaaban H, Miller JL, Johnson P, DeLeon S. Off-Label Medication use in Children, More Common than We Think: A Systematic Review of the Literature, J Okla State Med Assoc. 2018 October;111(8):776-783.
4. Bellis JR, Kirkham JJ, Nunn AJ, Pirmohamed M. Adverse drug reactions and off-label and unlicensed medicines in children: a prospective cohort study of unplanned admissions to a paediatric hospital. Br J Clin Pharmacol. 2014;77:545-53.

5. European Union. Regulation (EC) N¹901/2006 on Medicinal Products for Paediatric Use and Amending Regulation (EEC) $\mathrm{N}^{\circ}$ 1768/92, Directive 2001/20/EC, Directive 2001/83/EC and Regulation (EC) N²6/2004. Available at: http://ec.europa.eu/ health/human-use/paediatric-medicines/index_en.htmOR http://eur-lex.europa.eu/RECH_legislation.do. Accessed on June 2021

6. De Zen L, Marchetti F, Barbi E, Benini F. Off-label drugs use in pediatric palliative care. Ital J Pediatr. 2018 Nov 29;44(1):144. 
7. Gore R, Chugh PK, Tripathi CD, Lhamo Y, Gautam S. Pediatric off-label and unlicensed drug use and its implications. Curr Clin Pharmacol. 2017;12(1):18-25.

8. Oshikoya KA, Wharton GT, Avant D, Fenn NE, Lardieri A, Doe E, Sood BG, Taketomo C, Lieu P, Yen L, McMahon AW. Serious Adverse Events Associated with Off-Label Use of Azithromycin or Fentanyl in Children in Intensive Care Units: A Retrospective Chart Review. Pediatr Drugs, 2019;21(1):47-58.

9. Sachs A, Avant D, Lee C, Rodriguez W, Murphy D. Research letter: pediatric information in drug product labeling. JAMA. 2012;307(18):1914-5.

10. Ufer M, Kimland E, Bergman U. Adverse drug reactions and off-label prescribing for paediatric outpatients: a one-year survey of spontaneous reports in Sweden. Pharmacoepidemiol Drug Saf. 2004;13:147-52.

11. Aagaard L. Off-label and unlicensed prescribing of medicines in pediatric populations: occurrence and safety aspects. Basic Clin Pharmacol Toxicol. 2015;117(4):215-8.

12. Romanian National Agency for Medicines and Medical Devices, Nomenclature of medicines for human use Agentia Nationala a Medicamentelor si a Dispozitivelor Medicale din Romania, Nomenclatorul medicamentelor de uz uman. Internet. Available at: https://www.anm.ro/medicamente-de-uz-uman/nomenclatorul-medicamentelor-de-uz-uman/. Accessed on June, 2021 